\title{
COMPARISON OF PRECIPITATION STABLE ISOTOPES DURING WET AND DRY SEASONS IN A SUBTROPICAL MONSOON CLIMATE REGION OF CHINA
}

\author{
XIA, C. C. ${ }^{1,2}-$ CHEN, K. ${ }^{1,2}-$ ZHOU, J. ${ }^{1,2}-$ MeI, J. ${ }^{1,2}-$ LiU, Y. P. ${ }^{1,2}-$ LIU, G. D. ${ }^{1,2 *}$ \\ ${ }^{1}$ State Key Laboratory of Hydraulics and Mountain River Engineering, Sichuan University \\ Chengdu 610065, China \\ ${ }^{2}$ College of Water Resources and Hydropower, Sichuan University, Chengdu 610065, China \\ ${ }^{*}$ Corresponding author \\ e-mail: liugd988@163.com
}

(Received 25 ${ }^{\text {th }}$ Apr 2019; accepted 11 $1^{\text {th }}$ Jul 2019)

\begin{abstract}
Hydrogen and oxygen stable isotopes are natural tracers and have played an important role in the investigation of hydrological processes. In this paper, year-round precipitation samples were collected and measured in Chengdu, a subtropical monsoon climate region, to compare the stable isotope characteristics in precipitation and their influencing factors between dry and wet seasons. The results showed that the seasonal variation of $\delta \mathrm{D}$ and $\delta^{18} \mathrm{O}$ in precipitation was significant, and the isotopic values in precipitation in dry season were more enriched than those in wet season. The slope and intercept of local meteoric water line (LMWL) in Chengdu were lower than those in the southeast monsoon region of China but higher than those in north China, indicating the combined influence of ocean-source and inland water vapor. The slope of LMWL in dry season was obviously lower than that in wet season, revealing more intense sub-cloud secondary evaporation. The effect of temperature and precipitation was not significant in both seasons. Meteorological variables had greater influence on precipitation isotopes in wet season. D-excess had greater fluctuation during the dry season, reflecting more complex water vapor sources, which resulted in the influence of meteorological factors being masked.
\end{abstract}

Keywords: water circulation, monsoon activities, moisture source, meteorological parameters, subcloud secondary evaporation

\section{Introduction}

As an important part of natural material circulation, water circulation is the link connecting biosphere, atmosphere and hydrosphere. In the study of modern water cycle, hydrogen and oxygen stable isotopes in water bodies can provide a lot of information which is difficult to obtain by traditional hydrological methods due to its sensitive response to climate and environmental changes (Goller et al., 2005; Xie et al., 2011; Wang et al., 2017; Cai et al., 2017; Badaluta et al., 2019). Atmospheric precipitation is an important process of water circulation and a recharge source for rivers, lakes and groundwater. The stable isotopes in precipitation are affected by meteorological conditions, regional geographical position and weather patterns, and usually have a certain spatio-temporal variation law. Therefore, understanding the characteristics of stable isotopes in precipitation can help to understand the processes of water cycle and their feedback mechanism (Celle-Jeanton et al., 2004; Zhang et al., 2005; He et al., 2006). In 1961, the International Atomic Energy Agency (IAEA) and the World Meteorological Organization (WMO) collaborated to establish the Global Network of Isotopes in Precipitation (GNIP) to measure stable isotope data in global precipitation, and more than 800 monitoring sites have been established around the world. Since the 1960s, a large number of studies have been carried out around the world to reveal the 
variation characteristics of stable isotopes in precipitation of different climate types. For example, Guan et al. (2013) sampled and tested the event and intra-event samples of precipitation, and revealed the influence of synoptic weather system and water vapor source on precipitation isotopes in Flinders, an Australian Mediterranean climate region; Balagizi et al. (2018) reported the isotope values in Virunga, an African tropical climate region with strong evaporation, and suggested that the vapor from soil-plant evapotranspiration and that from lake surface evaporation are main causes of the depleted and enriched isotope compositions during wet and dry periods, respectively; a systematic study of stable isotopes was carried out on Crimean Peninsula, a region with different climate types, and temperature were proved to be the major factor correlated with the isotope values (Dublyansky et al., 2018).

Monsoon climate is widely distributed in the world. In the monsoon climate zone, monsoon is an important carrier of water vapor transport, and controls the spatial distribution and seasonal variation of precipitation. The change of the monsoon's onset time and intensity makes the amount and temporal distribution of precipitation in the monsoon region very uncertain, leading to the frequent occurrence of droughts and floods, which has a great impact on human production and life. Therefore, understanding the law of monsoon activities is of great significance to social and economic development. In recent years, many researchers have revealed the influence of monsoon on local meteorological conditions and water vapor source of precipitation by analyzing the stable isotope composition in precipitation in different monsoon regions around the world. For example, Pang et al. (2006) found that Lijiang is mainly controlled by large-scale India Depression System on the weather scale in summer by analysing the $\delta^{18} \mathrm{O}$ data in summer daily precipitation. Srivastava et al. (2015) implemented the early detection of the onset of monsoon by measuring the hydrogen and oxygen isotope compositions in atmospheric water vapor and precipitation in Ahmedabad, India. Peng et al. (2016) found that seasonal wind flow is the main factor affecting Yilan area in northeast Taiwan by analyzing the stable isotope compositions of precipitation and river water, and semi-quantitatively estimated the contribution ratio of air masses from different sources to river water volume. Xia et al. (2019) analyzed the monthly accuracy data of 15 stations provided by GNIP, and obtained the relationship between monsoon flow in Asian tropical monsoon region and isotopic composition in precipitation in different seasons. Qu et al. (2018) compared the isotopic characteristics and meteoric water lines of plum and typhoon rain, two typical precipitation types in monsoon region, and determined the relationship between isotopic composition and transport path and water vapor source.

Chengdu is located in southwest China and belongs to subtropical monsoon climate zone. During the wet season, the East Asian monsoon and the Indian monsoon meet here, bringing water vapor from the western Pacific and Indian Ocean; during the dry season, this area is controlled by the northwest monsoon from the high latitude inland. Due to the influence of the complex monsoon system, the stable isotope ratios in precipitation are significantly different between dry and wet seasons. Wu (2009) obtained the LMWL of Chengdu by analyzing precipitation isotope data of monthly accuracy from 1986 to 1998 provided by GNIP, and preliminarily analyzed the influence of precipitation, temperature and water vapor pressure on isotope compositions. However, the isotope data from GNIP is extremely limited, and those of monthly accuracy cannot reflect the variation characteristics of stable isotopes in precipitation at the weather scale. There is a lack of research on stable isotope in 
precipitation in this region. In this study, we collected and measured the stable isotope samples in precipitation during the dry and wet seasons in Chengdu in 2018, recorded local meteorological parameters, and discussed the effects of environmental factors and water vapor sources on the precipitation isotopes during the two seasons. The results of this paper will help to understand the atmospheric circulation and transport processes of water vapor in the southwest subtropical monsoon region of China, and provide isotopic evidence for studying the hydrological cycle mechanism in this region.

\section{Material and methods}

\section{Study area}

Chengdu, one of the largest cities in southwest China, located in the west of Sichuan Basin and the middle reaches of Minjiang River, is bounded by Longquan Mountain in the east and Qionglai Mountains in the west. Its altitude range is 398 4906 m. Chengdu has a subtropical humid monsoon climate with mild climate, distinct seasons and abundant rain. The long-term distribution characteristics of average monthly precipitation and temperature from Chengdu City Data Site of China Weather Network (www.weather.com.cn) are shown in Fig. 1(a).
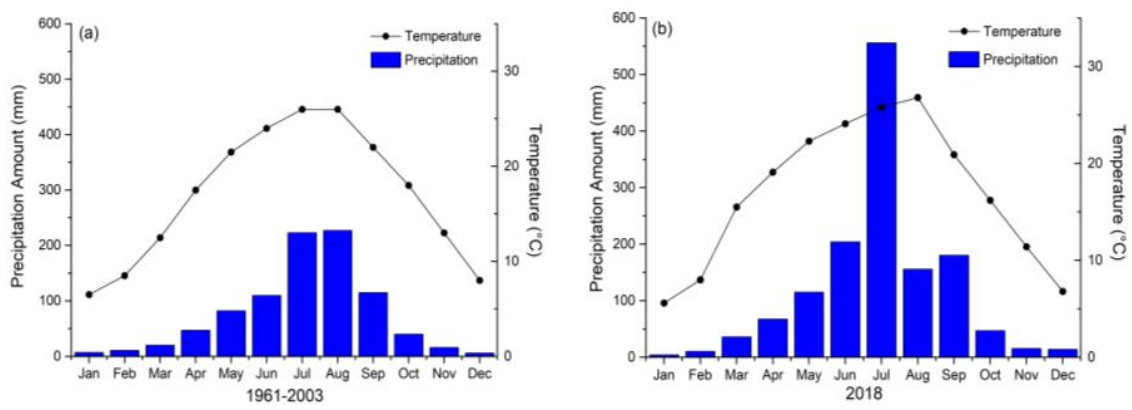

Figure 1. Monthly precipitation and average temperature in Chengdu in 2018

The highest and lowest monthly average temperature occurred in August and January, and the largest and smallest monthly precipitation occurred in July and January, respectively. According to the monitoring data provided by Chengdu Public Meteorological Service Website (http://pcc.scqx.gov.cn/sc_cd/fwcp/qhpj/), the average monthly temperature and precipitation in Chengdu in 2018 are shown in Fig. 1(b). In 2018 , although the variation trends of temperature and precipitation amount correspond to the multi-year average in Chengdu, the total annual precipitation shows a distinct high value of $1407 \mathrm{~mm}$, which can be attributed to the extremely large precipitation amount in July. The cumulative precipitation from June to September was $1096.9 \mathrm{~mm}$, accounting for $77.96 \%$ of the total, and that in other months was $310.1 \mathrm{~mm}$, accounting for $22.04 \%$ of the total. According to the temporal distribution of precipitation, June to September was divided into wet season and other months into dry season in Chengdu.

\section{Sample collection and analysis}

The sampling point for precipitation was located at the platform test site of the College of Water Resources and Hydropower, Sichuan University $\left(104.08{ }^{\circ} \mathrm{E}, 30.63{ }^{\circ} \mathrm{N}\right.$, $553 \mathrm{~m})$. This point is far away from local pollution sources and there are no tall 
buildings or trees blocking around. The geographical location of the sampling points is shown in Fig. 2. According to the IAEA/GNIP precipitation sampling guide, a simple water collecting device was set up: a plastic cylinder with a diameter of $50 \mathrm{~mm}$ and a height of $75 \mathrm{~mm}$ was fixed on the ground, with a PE plastic film covered above for collecting water; a $500 \mathrm{~mm}$ rain collecting bottle was placed in the cylinder, which connected with a funnel with a diameter of $15 \mathrm{~mm}$ and a table tennis ball was placed in the funnel to prevent evaporation. After a precipitation event, the rainwater was collected into a $20 \mathrm{~mL}$ plastic bottle, and then placed in a refrigerator for cold storage. The meteorological data (i.e. temperature, precipitation amount and relative humidity) during the precipitation were recorded according to the real-time measurements from Tiaosanta weather station, which is about $1 \mathrm{~km}$ away from the sampling site. The samples were collected and analyzed in an event precision, and multiple rainfalls occurring in one day were recorded as independent events respectively. The starting and ending times of an individual event are determined based on whether the rainfall intensity is greater than $0.1 \mathrm{~mm} / \mathrm{h}$. A total of 113 precipitation samples were collected in 2018, including 59 for wet season precipitation and 54 for dry season precipitation.

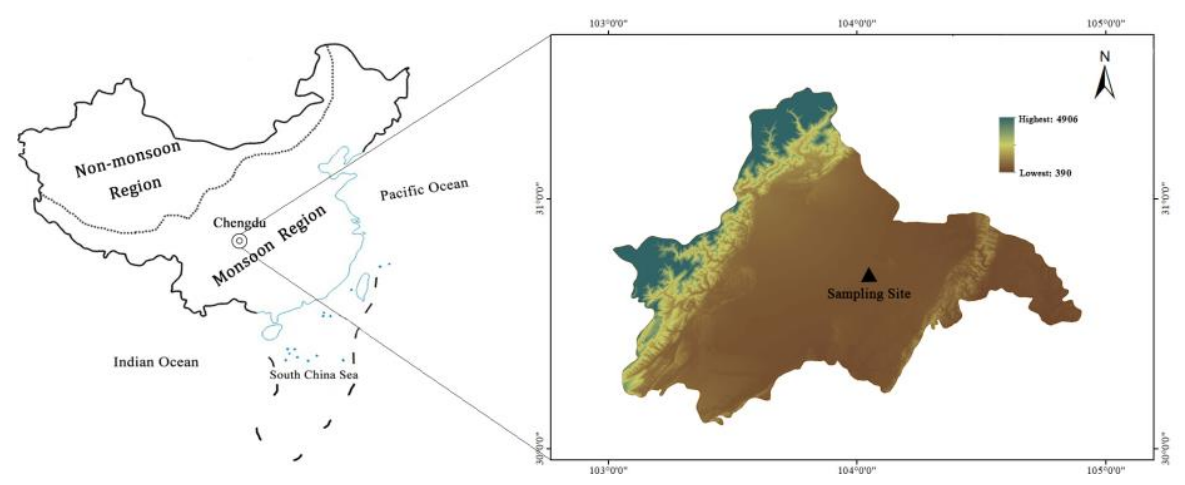

Figure 2. Location of the study area and sampling site

The samples were analyzed in College of Water Resources and Hydropower, Sichuan University, using the Triple-Liquid Water Isotope Analyzer produced by Los Gatos Research (LGR). The LGR analyzer uses spectrometry to measure stable isotope content in water and the measurement principle is OFF-AXIS Integrated Cavity Output Spectroscope (OA-ICOS). With the cooperation of a full-automatic sampler, the analyzer measures the samples automatically and continuously according to a computer program. Precipitation samples were filtered using $0.45 \mu \mathrm{m}$ filter membranes before measurement. Each sample was measured for six times and the first two measurements were rejected for their larger deviation from the actual value. Reference standard samples based on VSOMW-2 and SLAP-2 were measured at an interval of three precipitation samples to diagnose whether abnormalities occur during the measurement. The measurement results are expressed as per mil (\%o) deviation from Vienna Standard Mean Ocean Water (VSMOW). The formula is shown in Eq. 1:

$$
\delta^{18} \mathrm{O}(\delta \mathrm{D})=\frac{\mathrm{R}_{\text {sample }}-\mathrm{R}_{\text {standard }}}{\mathrm{R}_{\text {standard }}} \times 1000
$$

For $\delta \mathrm{D}$ and $\delta^{18} \mathrm{O}$, the instrumental errors are: $\delta \mathrm{D}<0.3 \%$, $\delta^{18} \mathrm{O}<0.08 \%$. 


\section{Statistical approaches}

Linear equations were established to evaluate the relationships between $\delta \mathrm{D}$ and $\delta^{18} \mathrm{O}$ and between meteorological parameters and isotope composition by the method of least square regression. The correlation coefficients and test of significance were analyzed by Pearson's method and two-tailed t tests, respectively. A sinusoidal periodic function was employed to fit the seasonal variation of isotopes. The statistical analysis in this study was conducted by Origin 9.0 and IBM SPSS Statistics 24.

\section{Results and discussion}

\section{Characteristics and seasonal variations of $\delta D$ and $\delta^{18} O$ in precipitation}

$\delta \mathrm{D}$ and $\delta^{18} \mathrm{O}$ showed obvious seasonal changes in precipitation events in Chengdu. In order to describe these changes, a trigonometric function fitting was employed in Fig. 3. The value of $\delta \mathrm{D}$ changed from -119.38 to 22.10 , with an arithmetic average of -43.65 and a precipitation weighted average of -50.52. The value of $\delta^{18} \mathrm{O}$ changed from -15.84 to 2.68 , with an arithmetic average of -6.60 and a precipitation weighted average of -9.01 . Wu (2009) reported the average of multi-year isotope values in Chengdu, which is $-5.6 \%$ in $\delta^{18} \mathrm{O}$ and $-40.7 \%$ in $\delta \mathrm{D}$, respectively.
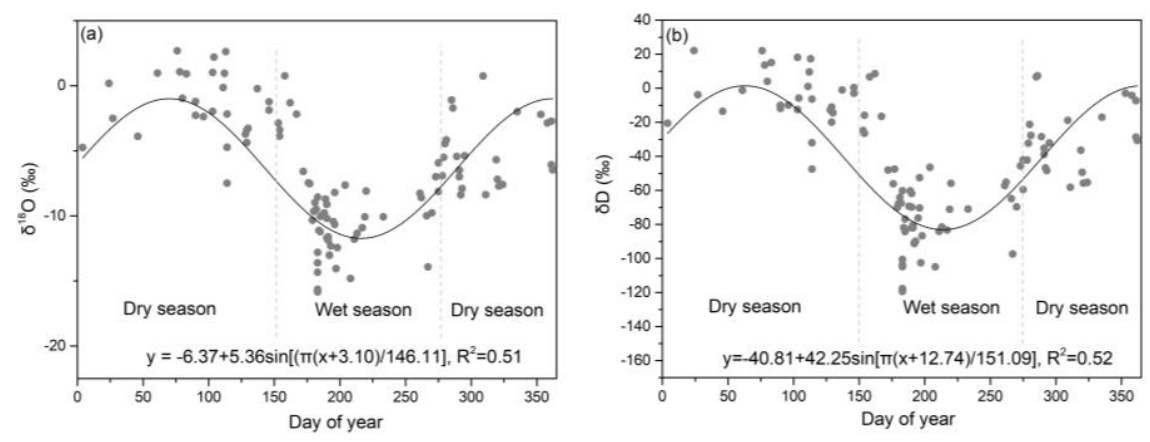

Figure 3. Seasonal variation of $\delta^{18} \mathrm{O}$ and $\delta D$ in precipitation in 2018

The average values of both isotopes during our study period are lower than those given by $\mathrm{Wu}$ (2009), which may be due to the depletion of heavy isotopes in air masses caused by the heavy summer precipitation in both Chengdu and other areas along the transport path. The maximum and minimum values of $\delta \mathrm{D}$ occurred in January and July, respectively, and those of $\delta^{18} \mathrm{O}$ occurred in March and July, respectively. $\delta \mathrm{D}$ and $\delta^{18} \mathrm{O}$ showed similar trends and periods of change, while $\delta \mathrm{D}$ showed greater amplitude, indicating that both isotopes in precipitation were affected by the same factors, but $\delta \mathrm{D}$ responded more strongly to environmental changes. Isotopes are enriched in the dry season and depleted in the wet season, which is similar to those in other areas of East Asia affected by subtropical monsoon climate, such as Wuhan, Bangkok and Guangzhou (He et al., 2006; Xie et al., 2011; Deng et al., 2016), but contrast to those in inland areas in the mid-high latitudes (Chen et al., 2017), indicating that the isotopic composition of precipitation in this area is closely related to the characteristics of atmospheric circulation and water vapor sources. Chengdu is located in southwest China, far away from the coastline and its distance from the Indian Ocean is similar to that from the Pacific Ocean. Influenced by different atmospheric circulation systems 
and multiple monsoons, the water vapor sources in this region are complex. During the wet season, Chengdu is jointly affected by Pacific High Pressure and Indian Ocean Low Pressure, and air masses with high humidity in this region came from the surface of the Pacific Ocean and Indian Ocean controlled by southeast and southwest monsoon. Due to frequent precipitation and evaporation caused by high temperature during longdistance transportation, isotopes in water vapor were strongly fractionated and D and ${ }^{18} \mathrm{O}$ in precipitation were depleted. During the dry season, Chengdu is affected by Mongolia High Pressure and Aleutian Low Pressure, and the northerly winds control the area. Air masses with low humidity and temperature originated from inland areas in the middle and high latitudes. During the transportation process, the temperature was lower, the precipitation along the transport path was less, and the "rainout effect" experienced by air masses was weaker, making $\mathrm{D}$ and ${ }^{18} \mathrm{O}$ in precipitation more enriched. $\delta^{18} \mathrm{O}$ and $\delta \mathrm{D}$ of more events deviated from the fitting line to a large extent in wet season, which may be due to the greater variations of temperature and precipitation, which have a greater impact on isotope fractionation during the rainfall processes.

\section{Local meteoric water line (LMWL) during wet and dry seasons}

The linear relationship between $\delta \mathrm{D}$ and $\delta^{18} \mathrm{O}$ in precipitation is named as meteoric water line. Craig (1961) first proposed the equation of global meteoric water line (GMWL) by investigating and analyzing the stable isotope compositions of different water bodies around the world: $\delta \mathrm{D}=8 \delta^{18} \mathrm{O}+10$; Zheng et al. (1983) reported the Chinese meteoric water line (CMWL) based on stable isotope measurements of precipitation in different regions of China: $\delta \mathrm{D}=7.9 \delta^{18} \mathrm{O}+8.2$. The linear relationship between $\delta \mathrm{D}$ and $\delta^{18} \mathrm{O}$ in precipitation in Chengdu was obtained by least squares method (Fig. 4a). The regression equation is given with Eq. 2:

$$
\delta \mathrm{D}=7.61 \delta^{18} \mathrm{O}+6.58\left(\mathrm{R}^{2}=0.98\right)
$$

The slope and intercept of meteoric water lines are affected by the water vapor sources, transport patterns, condensing temperature and the sub-cloud processes, and can be used to reflect the information of regional geography, meteorological conditions and water vapor source. Compared with GMWL and CMWL, the slope and intercept of the LMWL in Chengdu were small, indicating that the precipitation in Chengdu was affected by both the ocean-source and continental air masses on annual scale. Compared with other areas in China, the slope and intercept of LMWL in Chengdu were lower than those in the southeast coastal areas, such as Guangzhou, Changsha and Fuzhou (Xie et al., 2011; Yao et al., 2018; Xu et al., 2019), but higher than those in northern temperate climate regions, such as Lanzhou, Fengxiang, Ningwu and Beijing (Zhai et al., 2013; Chen et al., 2015; Zhao et al., 2018), indicating that the contribution of marine water vapor in the annual precipitation in Chengdu is lower than that in the southeast coast but higher than that in the northern region.

The LMWLs based on precipitation events during the wet and dry seasons is shown in Fig. 4 b. It can be observed that the LMWLs in wet and the dry seasons differed greatly, which reflected the differences in characteristics of isotope fractionation in the two seasons, which is mainly caused by atmospheric circulation patterns, water vapor sources and evaporation. In previous studies, the seasonal changes of LMWLs of different monsoon regions have been proved variable. The LMWLs of islands and coastal regions which are dominated by the oceanic water vapor all year round show 
slight variation between wet and dry seasons and plot closely to GMWL (Xia et al., 2019). The slope and intercept of LMWLs in monsoon marginal regions vary greatly seasonally, with high values in wet season and low values in dry (Zhao et al., 2018). In our study area, the slope and intercept of LMWL in wet season were close to those of GMWL and LMWL of low-latitude islands and coastal areas, indicating the dominance of oceanic air masses during this period, and precipitation was less affected by nonequilibrium fractionation. The slope and intercept of LMWL in dry season were significantly lower than those in wet season, but was close to those in mid-high latitudes, for example, Fengxiang in North China (Zhao et al., 2018), indicating that the region was controlled by inland dry air masses and significantly affected by sub-cloud secondary evaporation. Under dry conditions, non-equilibrium fractionation happens when raindrops fall in unsaturated atmosphere, leading to preferential fractionation of $D$ into atmosphere, relative enrichment of ${ }^{18} \mathrm{O}$, and fractionation ratio of $\mathrm{D}$ to ${ }^{18} \mathrm{O}$ to be lower than 8:1, which explains the lower slope and intercept of regression line.
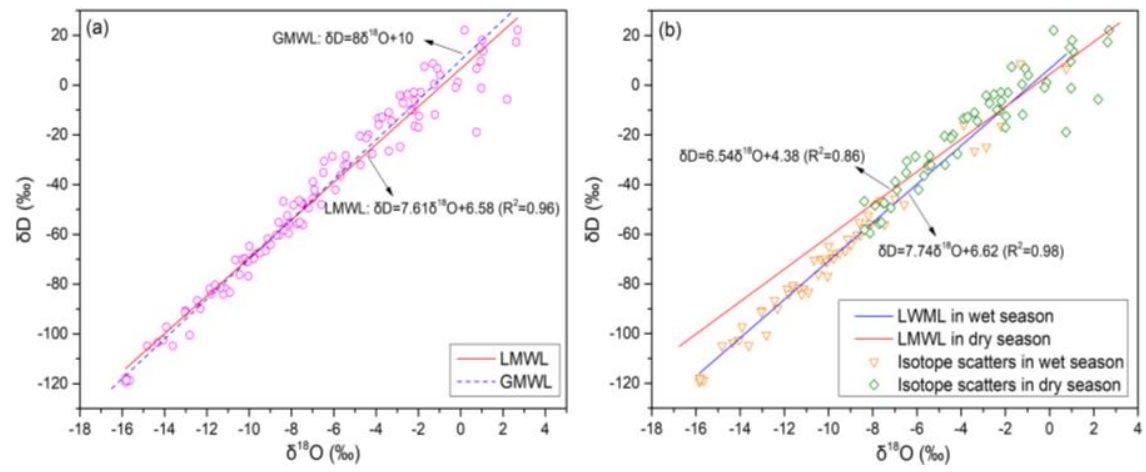

Figure 4. Year-round and seasonal correlation between $\delta^{18} O$ and $\delta D$ in precipitation

\section{Relationship between isotope compositions in precipitation and climatic factors}

\section{Precipitation effect}

Precipitation effect is an inverse correlation between precipitation stable isotopes and precipitation amount, which is generally significant in tropical and subtropical regions (Dansgaard, 1964). Regression analysis on the $\delta^{18} \mathrm{O}$-precipitation amount (P) relationship was performed in dry and wet seasons and the whole year in Chengdu using the least square method. Person's Method and two-tailed tests were used to reflect the degree of correlation and to perform significance test, respectively. The results are shown in Fig. 5. On the annual scale, $\delta^{18} \mathrm{O}-\mathrm{P}$ showed a significant negative correlation with a correlation coefficient ( $\mathrm{r}$ ) of -0.42 and passed the significance test of 0.01 confidence level. Compared with other regions in China's monsoon zone, the absolute value of $r$ of Chengdu is lower than that of tropical regions, such as Hong Kong ( -0.70 , 2015-2016), similar to that of subtropical regions, such as Guangzhou (-0.36, 2007-2009) and Chongqing (-0.40, 2010-2015), and higher than that of temperate regions, such as Fengxiang $(0.024,2016-2017)$ and Ningwu $(-0.05,2016-2017)$ (Xie et al., 2011; Zhao et al., 2018; Zhou and Li, 2018; Xia et al., 2019). The geographical difference of $r$, which is strong in low latitudes and weak in middle and high latitudes, is the same as the results of Araguas-Araguas et al. (1998) in Southeast Asia. This suggested that the influence of precipitation amount on isotopic composition of 
precipitation decreases with the increase of latitude. On the seasonal scale, the $\delta^{18} \mathrm{O}-\mathrm{P}$ correlations of the precipitation in both seasons failed the significance test of 0.05 confidence level and the $r$ values for dry and wet season were -0.11 and -0.26 . It is probably due to the complicated formation mechanism of stable isotopes in monsoon precipitation. The meteorological conditions at the source areas of water vapor determine the initial composition of the isotope, the "rainout effect" that isotopes in water vapor experience along the transport path and the recycled water vapor lead to changes in the isotopic composition. In monsoon climate regions, the sources and transport processes of water vapor are unstable and changeable due to the interaction of different monsoon systems, resulting in differences in stable isotopes in cloud when precipitation happens. Compared with the seasonal $r$ values $(-0.44$ and -0.22 for dry and wet seasons, respectively) of Changsha at the same latitude, the absolute value of $r$ of $\delta^{18} \mathrm{O}-\mathrm{P}$ relationship in wet season is relatively close between the two regions, while that of Chengdu is significantly lower in dry season (Wu et al., 2015). This may be due to the different division of dry and wet season between the two studies. In the study of Wu et al. (2015), the months of May and October, which is the transition periods between summer and winter monsoon with the most complicated water vapor sources, was not included either in dry or wet season. However, the two months were included in dry season in our study. The alternation and transformation of multiple monsoons resulted in the difference of isotope composition in clouds and subsequently in raindrops, which covered up the influence of precipitation amount.

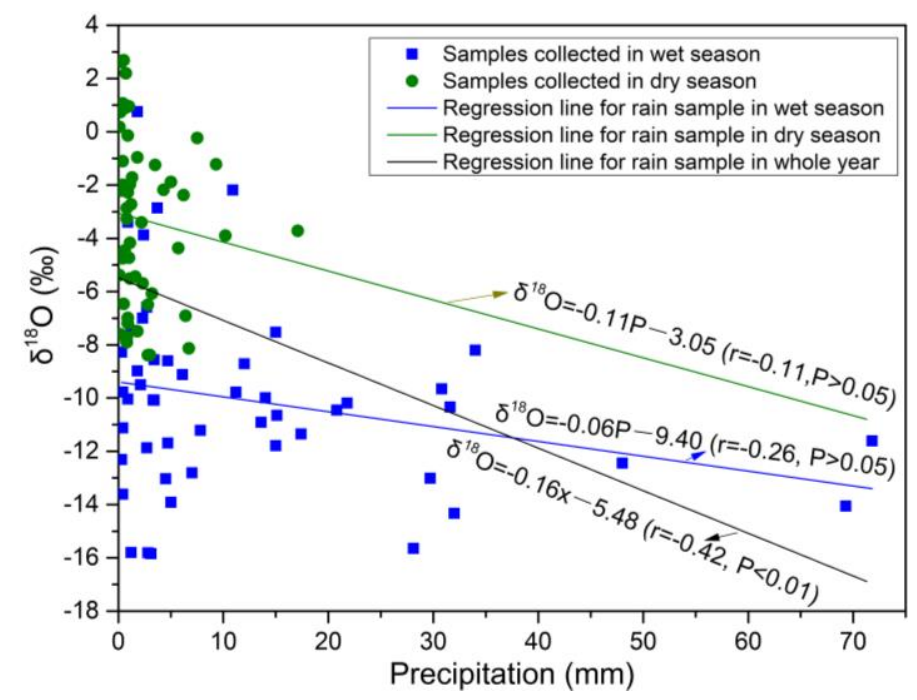

Figure 5. Linear relationship between $\delta^{18} \mathrm{O}$ and precipitation amount in both seasons and the whole year

According to Fig. 5, precipitation intensity is closely related to the variation range of isotopes. The isotopic composition of small-scale precipitation with an amount less than 10 in both seasons had a large variation range, but events with precipitation amount greater than $10 \mathrm{~mm}$ all showed low isotopic composition, especially for those occurred in wet season. To determine the influence degree of precipitation intensity on isotope composition, the precipitation data set in this study was divided into two groups (from 0 to $10 \mathrm{~mm}$ and from 11 to $70 \mathrm{~mm}$ ) to examine the $\delta^{18} \mathrm{O}-\mathrm{P}$ correlation separately. The results are shown in Table 1. Most precipitation events (88/113) during the study period 
happened with an intensity of less than $10 \mathrm{~mm}$ and those with a relatively strong intensity of 10-70 mm were monitored mainly in wet season. The correlation between $\delta^{18} \mathrm{O}$ and $\mathrm{P}(10-70 \mathrm{~mm})$ in the dry season is not obtained because of the scarce sample data. When the precipitation events with strong intensity are taken into consideration individually, the absolute values of $r$ of regression equations increase for both wet season $(0.45$ vs. 0.26$)$ and whole year $(0.49$ vs. 0.42$)$. While the absolute values of $r$ of the correlation between $\delta^{18} \mathrm{O}$ and $\mathrm{P}(0-10 \mathrm{~mm})$ are lower in seasonal and annual scale. This could be attributed to the influence of atmospheric circulation and external environment. For the one hand, most precipitation events with strong intensity happened in June and July, when the water vapor sourced from ocean area and travelled along a relative fixed path. The isotopes in the cloud layer were relatively stable when the rainfall happened. Reversely, the isotopes in the cloud layer were variable in dry season for the mixing of water vapor from different sources and transportation paths. For the other hand, the influence of isotope fractionation caused by sub-cloud evaporation, is more significant for small-scale precipitation than large one, which enhanced the variability in isotope composition.

Table 1. Relationship between $\delta^{18} \mathrm{O}$ and precipitation events with different intensity (from 0 to $10 \mathrm{~mm}$ and from 11 to $70 \mathrm{~mm}$ )

\begin{tabular}{c|c|c|c}
\hline Period & $\begin{array}{c}\text { Precipitation } \\
\text { intensity }\end{array}$ & $\begin{array}{c}\text { Number of } \\
\text { samples }\end{array}$ & $\boldsymbol{\delta}^{\mathbf{1 8} \mathbf{O}-\mathbf{P} \text { regression equation }}$ \\
\hline \multirow{2}{*}{ Whole year } & $<10 \mathrm{~mm}$ & 88 & $\delta^{18} \mathrm{O}=-0.49 \mathrm{P}-4.57(\mathrm{r}=-0.23, \mathrm{P}>0.05)$ \\
& $10-70 \mathrm{~mm}$ & 25 & $\delta^{18} \mathrm{O}=-0.09 \mathrm{P}-7.67(\mathrm{r}=-0.49, \mathrm{P}<0.01)$ \\
\hline \multirow{2}{*}{ Dry season } & $<10 \mathrm{~mm}$ & 52 & $\delta^{18} \mathrm{O}=-0.19 \mathrm{P}-2.91(\mathrm{r}=-0.13, \mathrm{P}>0.05)$ \\
& $10-70 \mathrm{~mm}$ & 2 & $/$ \\
\hline \multirow{2}{*}{ Wet season } & $<10 \mathrm{~mm}$ & 36 & $\delta^{18} \mathrm{O}=-0.30 \mathrm{P}-8.89(\mathrm{r}=-0.15, \mathrm{P}>0.05)$ \\
& $10-70 \mathrm{~mm}$ & 23 & $\delta^{18} \mathrm{O}=-0.07 \mathrm{P}-8.67(\mathrm{r}=-0.45, \mathrm{P}<0.01)$ \\
\hline
\end{tabular}

\section{Temperature effect}

According to the Rayleigh fractionation model, the condensation temperature of water vapor is related to the fractionation coefficient of the isotopes. Dansgaard (1964) defined the positive correlation between precipitation isotopes and temperature as temperature effect. The correlation between $\delta^{18} \mathrm{O}-$ Temperature $(\mathrm{T})$ in Chengdu was shown in Fig. 6. On the annual scale, there was a significant negative correlation between $\delta^{18} \mathrm{O}$ in precipitation and temperature in Chengdu, showing a "reverse temperature effect", which is inconsistent with the effect of temperature on isotope fractionation in physics. On the seasonal scale, there was no significant correlation between $\delta^{18} \mathrm{O}$ and temperature in either dry season or wet season. In previous studies, monthly accuracy data provided by GNIP presented that most (33/38) stations in Southeast Asia controlled by Pacific and Indian Ocean monsoon showed negative correlation or weak positive correlation $\left(\mathrm{r}^{2} \leq 0.24\right)$ between $\delta^{18} \mathrm{O}$ and temperature (Araguas-Araguas et al., 1998); the negative correlation between $\delta^{18} \mathrm{O}$ and temperature has also been widely observed in studies carried out in the monsoon regions of southern China, for example, in Chongqing $(r=-0.52)$ and Changsha $(r=-0.38)$, which is consistent with the results of this study (Wu et al., 2015; Zhou and Li, 2018). Recent studies in different regions of China show that the correlation between temperature and 
$\delta^{18} \mathrm{O}$ gradually strengthens from monsoon marginal area to inland area (with $\mathrm{r}$ value increasing from 0.16 to 0.83 ), indicating that the influence of temperature on isotope values enhances with the increase of latitude and decrease of monsoon intensity (Wang et al., 2019). These results indicate that the effect of temperature on the isotopic composition is closely related with monsoon activities and was masked by other effects.

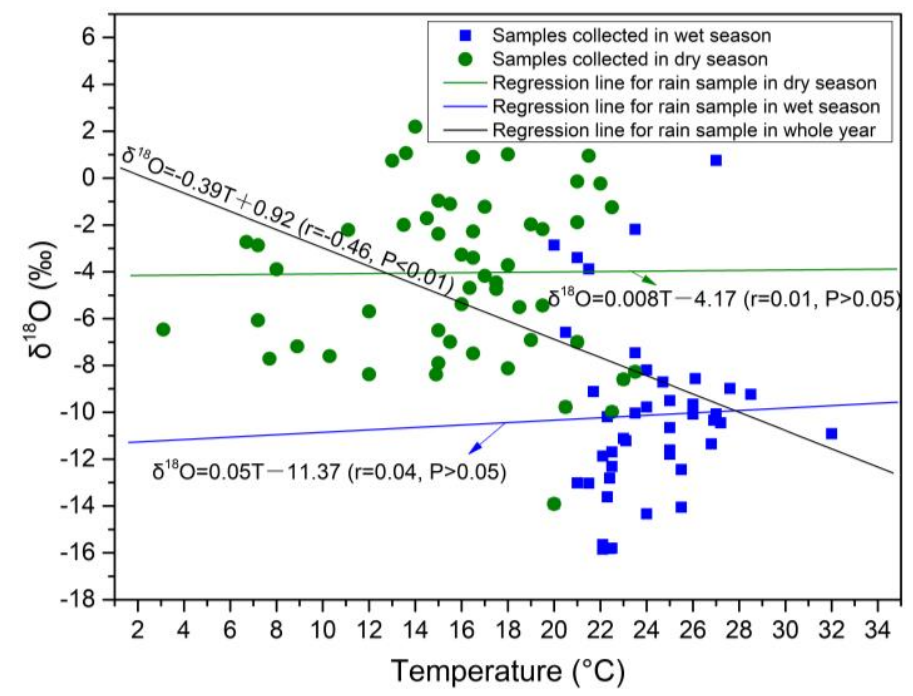

Figure 6. Linear relationship between $\delta^{18} \mathrm{O}$ and temperature in both seasons and the whole year

\section{Effect of local surface relative humidity}

Previous studies have shown that local surface relative humidity $(\mathrm{RH})$ determines the intensity of non-equilibrium isotope fractionation as it is related to evaporation conditions during the falling processes of raindrops, and is considered to be an important factor affecting the isotopic composition of precipitation (Zhang et al., 2007; Crawford et al., 2017). Correlation analysis was performed to determine the relationship between $\mathrm{RH}$ and precipitation $\delta^{18} \mathrm{O}$ on annual and seasonal scales (Fig. 7).

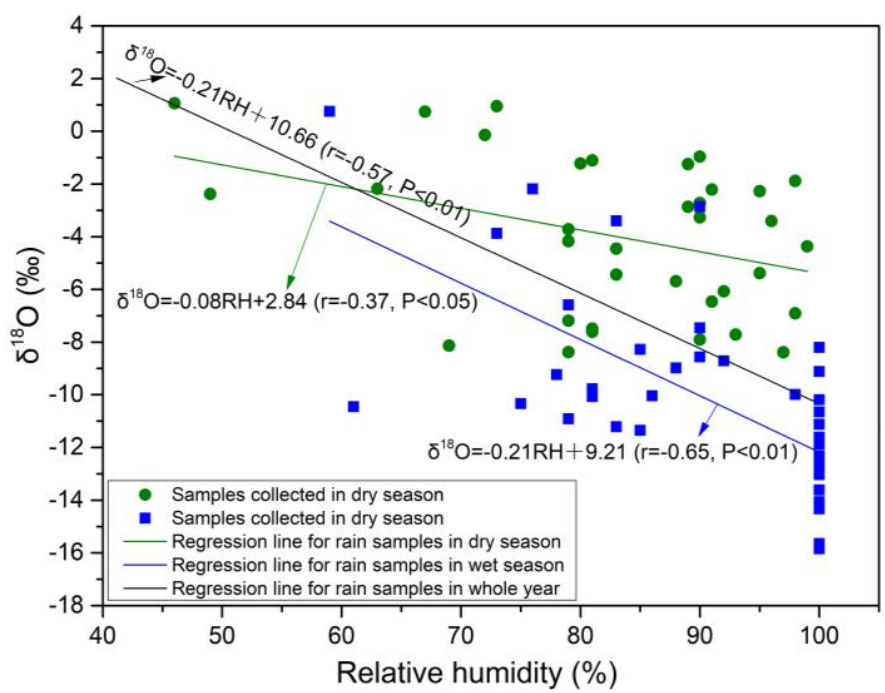

Figure 7. Correlation between $\delta^{18} \mathrm{O}$ and local surface relative humidity before rainfall in both seasons and the whole year 
Considering the effect of continuous precipitation on atmospheric saturation, the relative humidity in the atmosphere at the beginning of precipitation was selected. A significant negative correlation between $\delta^{18} \mathrm{O}$ and $\mathrm{RH}$ was observed on both annual and seasonal scales, indicating that evaporation conditions played an important role in the stable isotope composition in precipitation. Under unsaturated atmospheric conditions, the secondary evaporation of raindrops enriches heavy isotopes in the remaining water droplets during the process of falling from cloud to the ground due to the different kinetic energy of molecules in phase transformation. The enrichment degree of heavy isotopes is related to the unsaturated degree of the atmosphere. In the season when precipitation is scarce, the low relative humidity and strong sub-cloud evaporation increase the effect of non-equilibrium fractionation, resulting in an increase in $\delta^{18} \mathrm{O}$ value. When heavy or continuous precipitation occurs, the atmosphere approaches saturation and the effect of sub-cloud evaporation is weakened, leading to relatively depleted value of $\delta^{18} \mathrm{O}$. The absolute values of slope and correlation coefficient of $\delta^{18} \mathrm{O}-\mathrm{RH}$ regression in wet season were significantly higher than those in dry season, which may be due to the higher temperature in wet season accelerating the evaporation of raindrops during the sub-cloud processes, thus causing stronger non-equilibrium isotopic fractionation.

\section{Comprehensive effects of local climatic variables}

Understanding the relationship between meteorological factors and isotopes is the key to reflect climate change using the isotope method. When only the effect of a single factor on $\delta^{18} \mathrm{O}$ was considered, there is no expected significant correlation, which is not enough to explain the isotope changes in precipitation. Compared with unary linear regression, multiple linear regression can better reflect the common influence of multiple meteorological factors on stable isotopes in precipitation, which can be used to explore more complex relationships. Therefore, a multiple linear regression model containing temperature $(\mathrm{T})$, precipitation $(\mathrm{P})$, and relative humidity (RH) was established. Regression equations for the whole year, dry season and rainy season are shown in Eq. 3, Eq. 4 and Eq. 5, respectively.

$$
\begin{gathered}
\delta^{18} \mathrm{O}=0.26 \mathrm{~T}-0.05 \mathrm{P}-0.18 \mathrm{RH}+14.16\left(\mathrm{R}^{2}=0.477, \mathrm{P}<0.001\right) \\
\delta^{18} \mathrm{O}=0.43 \mathrm{~T}-0.01 \mathrm{P}-0.23 \mathrm{RH}+21.01\left(\mathrm{R}^{2}=0.506, \mathrm{P}<0.001\right) \\
\delta^{18} \mathrm{O}=0.21 \mathrm{~T}-0.14 \mathrm{P}-0.08 \mathrm{RH}+0.51\left(\mathrm{R}^{2}=0.164, \mathrm{P}<0.05\right)
\end{gathered}
$$

Compared with the correlation equation of $\delta^{18} \mathrm{O}-\mathrm{T}, \delta^{18} \mathrm{O}-\mathrm{P}$ and $\delta^{18} \mathrm{O}-\mathrm{RH}$, the correlation equation considering multiple variables showed higher $\mathrm{R}^{2}$ values on both annual and seasonal scales, indicating that different meteorological parameters have mutual influences due to their different relationships with precipitation isotopes. During the wet season, about $50.6 \%$ of the $\delta^{18} \mathrm{O}$ changes can be explained by local meteorological factors, while in the dry season, the proportion dropped to $16.4 \%$, indicating that the influence of local meteorological factors on isotopes was more masked by other variables in dry season than in rainy season. 


\section{Influence of moisture sources on stable isotopes in precipitation}

In order to describe the difference in imbalance degree of $\mathrm{D}$ and ${ }^{18} \mathrm{O}$ fractionation during two-phase conversion process, Dansgaard (1964) proposed the concept of $\mathrm{d}$-excess: $\mathrm{d}=\delta \mathrm{D}-8 \delta^{18} \mathrm{O}$. In the regional water cycle, $\mathrm{d}$-excess mainly depends on the meteorological conditions of the water vapor source, which is negatively correlated with surface humidity, and positively correlated with temperature. Therefore, d-excess can be used to indicate changes in the source of water vapor. The statistical information and temporal distribution of d-excess in Chengdu's precipitation in 2018 were shown in Table 2 and Fig. 8, respectively.

Table 2. Comparison of d-excess in precipitation events during dry and wet seasons

\begin{tabular}{c|c|c|c|c|c}
\hline Season & Maximum/\%o & Minimum/\%o & Range/\%o & Average/\%o & $\begin{array}{c}\text { Standard } \\
\text { deviation/\%o }\end{array}$ \\
\hline Dry & 21.13 & -24.85 & 45.97 & 9.16 & 9.48 \\
Wet & 19.09 & -1.95 & 21.04 & 9.17 & 4.34 \\
\hline
\end{tabular}

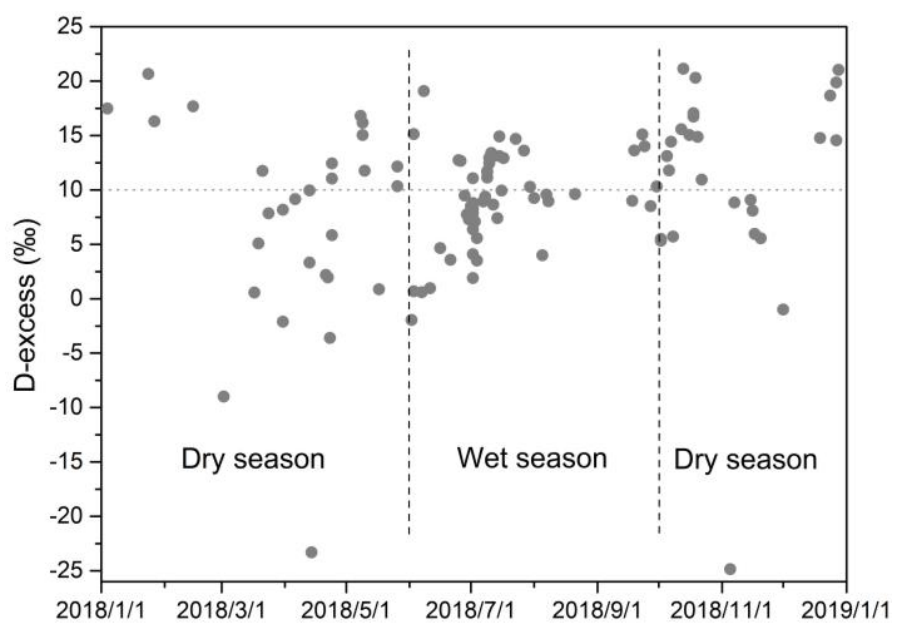

Figure 8. Temporal variation of d-excess in precipitation in 2018

Although the d-excess has similar average values in precipitation in dry and wet seasons, it shows a larger variation range and standard deviation in dry season. During the rainy season, the d-excess scatters fluctuate around the global average of 10 , indicating that the meteorological conditions of the water vapor source are relatively stable. During the dry season, the scatters of d-excess fluctuate greatly with time, indicating that the source of water vapor in the precipitation is variable. Changes in d-excess can be explained by monsoon activities. During the wet season, the southwest monsoon from the Indian Ocean and the Bay of Bengal, and the southeast monsoon from the South China Sea and the western Pacific controlled the region alternately. Water vapor of precipitation originated from tropical and subtropical oceans, and the weather conditions of the source were relatively close to the transportation path of air masses, so that the temporal variation of d-excess was slight. During the dry season, there were significant temporal differences in monsoon activities. From January to May, the monsoon controlling Chengdu had gradually transitioned from mid-high latitude inland monsoon to mid-low latitude ocean monsoon; from October to December, the 
inland monsoon controlled this area once again as oceanic monsoon subsided gradually. The complicated atmospheric circulation pattern and the contribution of recycled water vapor along the transport path, which is non-negligible under dry conditions, made the water vapor source in the dry season vary greatly in time, explaining the large fluctuation of the d value.

The complexity differences in the source of water vapor (which is related to the initial isotope content in water vapor) and the transport path (which is related to the cumulative precipitation of air masses before reaching the site) can also explain the significant differences in the correlation between $\delta^{18} \mathrm{O}$ and meteorological factors in dry and wet season. During the wet season, the temporal variation of the initial isotopic composition in ocean-source water vapor was small, and the uncertainty of transport distance and path was small, which caused smaller difference of isotopic composition in water vapor when the air masses reached Chengdu. During the dry season, Water vapor from different sources and variable transportation paths made the isotopic composition of water vapor over Chengdu significantly different, thus masking the influence of local meteorological conditions on the isotopic composition.

\section{Conclusion}

In this paper, a comparison of the stable isotope characteristics during dry and wet seasons in a subtropical monsoon climate region was carried out based on the year-round measured data. The results showed that the stable isotopes in precipitation presented obvious seasonal changes, more negative in wet season and less negative (or positive) in dry season. The LMWL of Chengdu lied between the southeast coast and the northern inland region of China, indicating that Chengdu is affected by both ocean and inland water vapor. The slope of LMWL in dry season was lower than that in rainy season, which indicated that the precipitation in dry season was affected by more intense sub-cloud secondary evaporation. The influence of local meteorological factors on isotopes was analyzed by simple and multiple regressions. The temperature effect and precipitation effect were not significant in both seasons, reflecting the masking effect of other factors. The relative humidity showed a negative correlation with the isotopes during dry and wet seasons, and the correlation difference reflected the strength of sub-cloud secondary evaporation. In a multiple regression that considered the combined influence of multi-factors, the correlation coefficient showed an improvement. The changes in water vapor source under the influence of monsoon reflected by $\mathrm{d}$ excess explained the correlation between meteorological factors and isotopic composition in dry and wet seasons. Compared with the rainy season, more complicated water vapor sources and transport paths in the dry season made the impact of local meteorological variables on isotopes be masked to a greater extent.

\section{REFERENCES}

[1] Araguas-Araguas, L., Froehlich, K., Rozanski, K. (1998): Stable isotope composition of precipitation over southeast Asia. - Journal of Geophysical Research-Atmospheres 103: 28721-28742.

[2] Badaluta, C. A., Persoiu, A., Ionita, M., Nagavciuc, V., Bistricean, P. I. (2019): Stable H and $\mathrm{O}$ isotope-based investigation of moisture sources and their role in river and 
groundwater recharge in the NE Carpathian Mountains, East-Central Europe. - Isotopes in Environmental and Health Studies 55.

[3] Balagizi, C. M., Kasereka, M. M., Cuoco, E., Liotta, M. (2018): Influence of moisture source dynamics and weather patterns on stable isotopes ratios of precipitation in CentralEastern Africa. - Science of the Total Environment 628-629: 1058-1078.

[4] Cai, Z. Y., Tian, L. D., Bowen, G. J. (2017): ENSO variability reflected in precipitation oxygen isotopes across the Asian Summer Monsoon region. - Earth and Planetary Science Letters 475: 25-33.

[5] Celle-Jeanton, H., Gonfiantini, R., Travi, Y., Sol, B. (2004): Oxygen-18 variations of rainwater during precipitation: application of the Rayleigh model to selected rainfalls in Southern France. - Journal of Hydrology 289: 165-177.

[6] Chen, F. L., Zhang, M. J., Ma, Q., Wang, S. J., Li, X. F., Zhu, X. F. (2015): Stable isotopic characteristics of precipitation in Lanzhou City and its surrounding areas, Northwest China. - Environmental Earth Sciences 73: 4671-4680.

[7] Chen, F. L., Zhang, M. J., Wang, S. J., Qiu, X., Du, M. X. (2017): Environmental controls on stable isotopes of precipitation in Lanzhou, China: An enhanced network at city scale. - Science of the Total Environment 609: 1013-1022.

[8] Craig, H. (1961): Isotopic Variations In Meteoric Waters. - Science 133: 1702-1703.

[9] Crawford, J., Hollins, S. E., Meredith, K. T., Hughes, C. E. (2017): Precipitation stable isotope variability and subcloud evaporation processes in a semi-arid region. Hydrological Processes 31: 20-34.

[10] Dansgaard, W. (1964): Stable Isotopes In Precipitation. - Tellus 16: 436-468.

[11] Deng, Z. M., Zhang, X., Pan, G. Y. (2016): Variations of Hydrogen and Oxygen Isotopes in Meteoric Precipitation in Wuhan, China. - Journal of Yangtze River Scientific Research Institute 33: 12-17.

[12] Dublyansky, Y. V., Klimchouk, A. B., Tokarev, S. V., Amelichev, G. N., Langhamer, L., Spotl, C. (2018): Stable isotopic composition of atmospheric precipitation on the Crimean Peninsula and its controlling factors. - Journal of Hydrology 565: 61-73.

[13] Goller, R., Wilcke, W., Leng, M. J., Tobschall, H. J., Wagner, K., Valarezo, C., Zech, W. (2005): Tracing water paths through small catchments under a tropical montane rain forest in south Ecuador by an oxygen isotope approach. - Journal of Hydrology 308: 6780 .

[14] Guan, H. D., Zhang, X. P., Skrzypek, G., Sun, Z., Xu, X. (2013): Deuterium excess variations of rainfall events in a coastal area of South Australia and its relationship with synoptic weather systems and atmospheric moisture sources. - Journal of Geophysical Research-Atmospheres 118: 1123-1138.

[15] He, Y. Q., Pang, H. X., Theakstone, W. H., Zhang, Z. L., Lu, A. G., Gu, J. (2006): Isotopic variations in precipitation at Bangkok and their climatological significance. Hydrological Processes 20: 2873-2884.

[16] Pang, H. X., He, Y. Q., Lu, A. G., Zhao, J. D., Ning, B. Y., Yuan, L. L., Song, B. (2006): Synoptic-scale variation of $\delta^{18} \mathrm{O}$ in summer monsoon rainfall at Lijiang, China. - Chinese Science Bulletin 51: 2897-2904.

[17] Peng, T. R., Huang, C. C., Chen, C. T., Chen, J. E., Liang, W. J. (2016): Using stable hydrogen and oxygen isotopes to reveal monsoonal and related hydrological effects on meteoric water in the Western Pacific monsoon region: A case study of the Ilan region, northeastern Taiwan. - Journal of Asian Earth Sciences 128: 105-115.

[18] Qu, S. M., Chen, X. Q., Wang, Y. F., Shi, P., Shan, S., Gou, J. F., Jiang, P. (2018): Isotopic Characteristics of Precipitation and Origin of Moisture Sources in Hemuqiao Catchment, a Small Watershed in the Lower Reach of Yangtze River. - Water 10.

[19] Srivastava, R., Ramesh, R., Gandhi, N., Jani, R. A., Singh, A. K. (2015): Monsoon onset signal in the stable oxygen and hydrogen isotope ratios of monsoon vapor. - Atmospheric Environment 108: 117-124. 
[20] Wang, T., Chen, J. S., Ge, J., Zhan, L. C. (2017): Isotopic evidence of allogenic groundwater recharge in the Northern Ordos Basin. - Journal of Radioanalytical and Nuclear Chemistry 314: 1595-1606.

[21] Wang, L., Dong, Y., Han, D., Xu, Z. (2019): Stable isotopic compositions in precipitation over wet island in Central Asia. - Journal of Hydrology 573: 581-591.

[22] Wu, X. D. (2009): Stable isotope compositions for meteoric water from Chengdu and their implication of climate. - Acta Geologica Sinica 29: 52-58.

[23] Wu, H., Zhang, X., Xiaoyan, L., Li, G., Huang, Y. (2015): Seasonal variations of deuterium and oxygen-18 isotopes and their response to moisture source for precipitation events in the subtropical monsoon region. - Hydrological Processes 29: 90-102.

[24] Xia, C. C., Liu, G. D., Mei, J., Meng, Y. C., Liu, W., Hu, Y. (2019): Characteristics of hydrogen and oxygen stable isotopes in precipitation and the environmental controls in tropical monsoon climatic zone. - International Journal of Hydrogen Energy 44: 54175427.

[25] Xie, L., Wei, G., Deng, W., Zhao, X. (2011): Daily $\delta 18 \mathrm{O}$ and $\delta \mathrm{D}$ of precipitations from 2007 to 2009 in Guangzhou, South China: Implications for changes of moisture sources. - Journal of Hydrology 400: 477-489.

[26] Xu, T., Sun, X. S., Hong, H., Wang, X. Y., Cui, M. Y., Lei, G. L., Gao, L., Liu, J., Lone, M. A., Jiang, X. Y. (2019): Stable isotope ratios of typhoon rains in Fuzhou, Southeast China, during 2013-2017. - Journal of Hydrology 570: 445-453.

[27] Yao, T. C., Zhang, X. P., Guan, H. D., Zhou, H., Hua, M. Q., Wang, X. J. (2018): Climatic and environmental controls on stable isotopes in atmospheric water vapor near the surface observed in Changsha, China. - Atmospheric Environment 189: 252-263.

[28] Zhai, Y. Z., Wang, J. S., Zhang, Y., Teng, Y. G., Zuo, R., Huan, H. (2013): Hydrochemical and isotopic investigation of atmospheric precipitation in Beijing, China. - Science of the Total Environment 456: 202-211.

[29] Zhang, X. P., Sun, W. Z., Liu, J. M. (2005): Stable isotopes in precipitation in the vapor transport path in Kunming of Southwest China. - Resources and Environment in the Yangtze Basin 14: 665-669.

[30] Zhang, X. P., Liu, J. M., Sun, W. Z., Huang, Y. M., Zhang, J. M. (2007): Relations between oxygen stable isotopic ratios in precipitation and relevant meteorological factors in southwest China. - Science in China Series D-Earth Sciences 50: 571-581.

[31] Zhao, P., Tan, L., Zhang, P., Wang, S., Cui, B., Li, D., Xue, G., Cheng, X. (2018): Stable Isotopic Characteristics and Influencing Factors in Precipitation in the Monsoon Marginal Region of Northern China. - Atmosphere 9: 97.

[32] Zheng, S. H., Hou, G. F., Ni, B. L. (1983): The studies of hydrogen and oxygen stable isotopes in atmospheric precipitation in China. - Chinese Science Bulletin 13: 801-806.

[33] Zhou, J. L., Li, T. Y. (2018): A tentative study of the relationship between annual delta O-18 \& delta D variations of precipitation and atmospheric circulations-A case from Southwest China. - Quaternary International 479: 117-127. 